\title{
O TRABALHO ESCRAVO CONTEMPORÂNEO: CONCEITO E ENFRENTAMENTO À LUZ DO TRABALHO JURÍDICO E PASTORAL DO FREI HENRI BURIN DES ROZIERS
}

Contemporary slave labor: concept and confrontation in the light of the legal and pastoral work of friar Henri Burin des Roziers El trabajo esclavo contemporáneo: concepto y enfrentamiento a la luz del trabajo jurídico y pastoral del fray Henri Burin des Roziers

\section{MOISÉS PEREIRA SILVA ${ }^{{ }^{*}}$}

\footnotetext{
' Pontifícia Universidade Católica de São Paulo ( PUC-SP), São Paulo-SP, Brasil.

* Doutor em História Social pela Pontifícia Universidade Católica de São Paulo (PUC-SP) e professor da Universidade Estadual de Goiás (UEG), Campus Uruaçu-GO, Brasil. (mosico100@gmail.com), ORCID iD: https://orcid.org/0000-0003-2712-3820
}

Artigo recebido em 10 de novembro de 2018 e aceito para publicação em 8 de março de 2019. 


\section{RESUMO}

A denúncia de trabalho escravo na Amazônia, publicada por Pedro Casaldáliga (1970; 1971), embora caracterizasse o crime e orientasse a ação dos agentes pastorais, esbarrou nos limites da legislação brasileira. 0 propósito deste texto é demonstrar como o trabalho jurídico-pastoral de Henri Burin des Roziers, somado a outros sujeitos e instituições, contribuiu para a reconfiguração do conceito de trabalho escravo, o que repercutiu no campo jurídico e foi fundamental para o desenvolvimento e 0 aprimoramento de políticas públicas de enfrentamento à exploração dos trabalhadores do campo.

PALAVRAS-CHAVE: Trabalho escravo contemporâneo; Legislação; Engajamento.

\section{ABSTRACT}

The denunciation of slave labor in the Amazon published by Pedro Casaldáliga (1970; 1971), although characterizing crime and guiding the action of pastoral agents, ran up against the limits of Brazilian legislation. The purpose of the present text is to demonstrate how the legal and pastoral work of Henri Burin des Roziers, in addition to other subjects and institutions, contributed to the reconfiguration of the concept of slave labor, which had repercussions in the legal field and was fundamental for the development and improvement of policies to combat the exploitation of rural workers.

KEYWORDS: Contemporary slave labor; Legislation; Engagement.

\section{RESUMEN}

La denuncia de trabajo esclavo en la Amazonia publicada por Pedro Casaldáliga (1970; 1971), aunque caracterizaba el crimen y orientaba la acción de los agentes pastorales, chocó en los límites de la legislación brasileña. El propósito de este texto es demostrar cómo el trabajo jurídico-pastoral de Henri Burin des Roziers, sumado a otros sujetos e instituciones, contribuyó a la reconfiguración del concepto de trabajo esclavo, lo que repercutió en el campo jurídico y fue fundamental para el desarrollo y perfeccionamiento de políticas públicas de enfrentamiento a la explotación de los trabajadores del campo.

PALABRAS CLAVE: Trabajo esclavo contemporáneo; Legislación; Compromiso. 
abolição da escravidão legal, em 1888, e a convicção, especialmente a institucionali-
zada, de que a interdição normativa basta para encerrar um fenômeno, impõe, mais do que em outros temas, a necessidade, aos que estudam o trabalho escravo contemporâneo, de explicar conceitualmente a matéria de que se ocupam. Desde as primeiras pesquisas acadêmicas publicadas sobre o assunto, os pesquisadores procuraram responder a essa contingência. Nesse sentido, pode parecer repetitivo retomar a questão do conceito de trabalho escravo. No entanto, essa explicação neste texto se justifica para que se introduza o tema a partir de um aspecto do conceito, fundamental para o conjunto da discussão, e, ao mesmo tempo, novo do ponto de vista da abordagem histórica. 0 conceito de trabalho escravo contemporâneo adotado aqui compreende uma construção histórica na qual se revela a coragem de homens e mulheres que denunciam, e dos atores, - entre eles a Comissão Pastoral da Terra (CPT), que se engajam na defesa desses sujeitos, e nisso compreendem a degradação humana como indício de relação escravista, e a atuação dos agentes públicos que, lidando com uma lei insuficiente, serão, gradativa e parcialmente, convencidos do entendimento dos agentes pastorais, que lhes sensibilizarão a ponto de engajá-los a buscar a alteração da lei, passo fundamental para a legitimidade das denúncias e para a ação e produção discursiva dos agentes pastorais.

No campo da ciência histórica, há uma tendência à percepção dos conceitos como possibilidades dinâmicas, e Certeau (1982) ajuda a entender essa dinâmica. Não se trata de mudança da ciência no sentido de produção de saber válido, nem da relatividade do saber científico, mas da dinâmica das significações culturais, dos valores e dos contextos em que se dão as experiências humanas. Reinhart Koselleck, respeitada a especificidade da sua discussão, chama a atenção para a relação entre o conceito e o seu conteúdo histórico. Para ele (1992: 136), "todo conceito é não apenas efetivo enquanto fenômeno linguístico; ele é também imediatamente indicativo de algo que se situa para além da língua". 0 estudo de Marcelo Gantus Jasmin e João Feres Júnior (2006: 30) avalia que o ponto convergente na diversidade do debate sobre a história dos conceitos é a percepção sobre "as continuidades nas camadas de significados de determinados conceitos" e, simultaneamente, a percepção da "novidade histórica de seus usos determinados". Poder-se-ia, no limite, pensar a questão conceitual à luz do mundo líquido de Zigmam Bauman (2013). Essas são perspectivas que ajudam a entender a instabilidade do conceito de trabalho escravo contemporâneo. E quanto mais o conceito avança, no sentido de traduzir a realidade, mais fica evidente o enraizamento e a longa duração1 desse fenômeno social e suas metamorfoses.

Do ponto de vista dos pesquisadores, Neide Esterci, em 1987, foi pioneira nessa discussão, definindo a peonagem como sinônimo de trabalho escravo. Seu interesse pelo tema, em 
princípios da década de 1980, teria sido provocado pelo trabalho dos agentes da CPT Araguaia-Tocantins. Para ela (1987: 97), a peonagem é uma "forma de subordinação do trabalho distinta do assalariamento tipicamente capitalista, considerando a instituição da dívida, a figura do intermediário e o contrato de remuneração por produção como elementos que compõem a relação". Outras características importantes, como o aliciamento, geralmente distante do local em que se desenvolvem as atividades, são acrescidas no curso de seus estudos (idem; 1996; 2008). Em Esterci, servidão, peonagem e escravidão por dívida são termos correlatos.

Na década de 1990, teve significativa repercussão no meio acadêmico o trabalho de José de Souza Martins (1995, 1997). O autor, partindo da tipologia definida por Casaldáliga (1971), discute a peonagem como consequência da reprodução do capital, que, em circunstâncias desfavoráveis, se reinventa, lançando mão da exploração extrema para conseguir a acumulação, mesmo não sendo capitalistas os meios dessa acumulação. Sua sociologia do trabalho considera que, diferentemente da escravidão clássica, "no Brasil se firmou no cativeiro do negro a peonagem [...] marcada por extrema violência física contra os trabalhadores, em alta proporção, culminando com o assassinato daqueles que procuram fugir" (Martins, 1995: 1). Provavelmente por seus espaços de atuação, inclusive assessorando a própria CPT, José de Souza Martins se tornou uma referência na produção de saberes sobre os conflitos sociais no campo, especialmente na Amazônia. Apesar disso, sua tese apresenta problemas graves. 0 principal é o fato de que ele considera a peonagem consequência dos desafios à acumulação capitalista impostos pelo meio. No entanto, na década de 1970, período de maior difusão da escravidão contemporânea, as empresas escravistas encontravam terreno amplamente favorável tanto no que diz respeito à infraestrutura, com a abertura de estradas, quanto no que diz respeito a subsídio e concessão de crédito. Outro fator ignorado por ele é que a violência extrema não era o único caráter da peonagem. A economia moral, que constrangia o trabaIhador ao esforço de quitação da dívida, também funcionou como elemento imprescindível na estrutura do processo de peonagem. ${ }^{2}$

Embora as condições degradantes fizessem parte das denúncias de trabalho escravo, até a revisão do artigo 149, do Código Penal, a ênfase das denúncias era sobre circunstâncias em que a mão de obra era obtida sob coação. Os agentes pastorais entendiam, no entanto, que a coação era uma realidade complexa. Nesse sentido, ela podia manifestar-se sob a forma da simples ameaça à integridade física, mas também de forma mais sútil, como na retenção de documentos dos trabalhadores. 0 trabalhador geralmente se sentia coagido a pagar a dívida contraída, mesmo essa sendo uma ficção, pelo dever moral de honrar com o devido e esse se eu devo, eu pago (Figueira, 2004; Rampazzo, 2007), e constitui o elo fundamental na cadeia 
que alimenta o trabalho escravo. Do ponto de vista do fazendeiro, a possibilidade de não pagamento da dívida justificava a violência contra o trabalhador. Não haveria a dívida, contudo, se não houvesse estratégias como o aliciamento distante da área de trabalho, que oportunizava a cobrança da passagem, da alimentação e da hospedagem, ou, ainda, a estratégia de montar o barracão no local de trabalho e cobrar valores majorados pela alimentação precária. Nos casos mais extremos, como ocorreu em Piraquê, à época norte de Goiás (Silva, 2016), ou em algumas fazendas do sul do Pará (Figueira, 2004; 2008), o fazendeiro simplesmente mandava matar o peão ${ }^{3}$ como forma de não lhe pagar pelo serviço realizado.

0 que se chamou de peonagem, trabalho forçado, escravidão por dívida ou servidão, tinha como base as denúncias feitas por dom Pedro Casaldáliga no início da década de 1970. Mesmo na tese de Ricardo Rezende Figueira (2004), seguramente o pesquisador brasileiro mais reconhecido entre os que estudam esse tema, a constituição do conceito de trabalho escravo ainda tem como referência fundamental a construção discursiva de Casaldáliga. No entanto, especialmente a partir do engajamento de frei Henri des Roziers, o avanço se manifestou não apenas na forma de apresentação das denúncias de casos de trabalho escravo mais formais do ponto de vista jurídico -, como também, e sobretudo, pelo desnudamento da insuficiência da legislação brasileira na condição de remédio para o crime que era denunciado e, por consequência, em proposições que resultaram numa mudança conceitual que passou a tipificar o trabalho escravo, deslocando o foco da coação para a criminalização das relações trabalhistas em que a dignidade do trabalhador está ameaçada, o que inclui a coação, mas alcança formas mais sutis de exploração, como as condições degradantes de trabalho e a jornada exaustiva, por exemplo.

0 que é paradigmático em Casaldáliga (1970; 1971), além da denúncia à permanência da escravidão supostamente suplantada, é a tipificação das formas características dessa escravidão, e isso fica evidente na forma das denúncias da CPT e, como se demonstrou, nas produções teóricas posteriores sobre o tema. 0 aliciamento, as estratégias de produção da dívida, 0 isolamento, as condições degradantes de trabalho e, mormente, a violência física em vista do cativeiro do trabalhador são os elementos constituintes da escravidão apresentadas no texto pastoral do bispo de São Felix do Araguaia, no Mato Grosso. Essas denúncias constituíram o parâmetro para a ação dos demais agentes pastorais que, sobretudo entre o final da década de 1980 e a década de 1990, se engajaram no enfrentamento ao trabalho escravo. 0 problema é que, embora os documentos de Casaldáliga indicassem uma diretriz aos agentes da CPT, faltava aos agentes públicos, a quem eram apresentadas as denúncias, dispositivos jurídicos que constituíssem possibilidade efetiva de enquadramento dos culpados e, por consequência, 
de repressão a esse crime. Os noticiários sobre trabalho escravo na Amazônia, desde 0 início da década de 1970 (Bispo de...1972; Coutinho, 1973)4 e a produção acadêmica não deixavam dúvida quanto à existência do fenômeno. Mas isso, do ponto de vista dos agentes públicos, não era suficiente.

0 texto do artigo 149 do Código Penal criminalizava reduzir alguém à condição análoga à de escravo, mas não dizia o que isso significava. Assim, nos casos em que as denúncias eram recepcionadas, pelo menos até o início do século XXI, a indefinição de o que seria condição análoga à de escravo corroborava, nas diligências de verificação in loco, a opção dos agentes públicos pela negação do fato denunciado. Isso fica evidente nos relatórios produzidos pela Polícia Federal, que investigou a Fazenda Brasil Verde ${ }^{5}$ atendendo solicitação do Ministério Público Federal (MPF), que, por sua vez, atendia denúncia de trabalho escravo e de desaparecimento de dois menores - Iron Canuto da Silva, de 17 anos e Miguel Ferreira da Cruz, de 16 anos - apresentada pela CPT.

No caso da Fazenda Brasil Verde, a denúncia da CPT foi apresentada no final de 1988. Em fevereiro de 1989, a Polícia Federal (PF) empreendeu diligência, conforme Ordem de Missão (OM) 018/1989, ${ }^{6}$ além de na fazenda denunciada, de propriedade da família Quagliato, também em outras fazendas do mesmo grupo. 0 trabalho nessas fazendas era coordenado por empreiteiros, conhecidos na região como gatos; as condições de trabalho eram precárias, e não havia contratação dos empregados, que trabalhavam sob a promessa de um pagamento que não ocorria sob o argumento, da parte dos empregadores, de endividamento dos trabaIhadores. Segundo a OM 018/89, com a aproximação da polícia, o empreiteiro da fazenda fugiu. Esse quadro se repete em outros relatórios de diligências em fazendas do sul do Pará, como no relatório da OM 036/1992 da PF, que relatam diligências de 1989 nas fazendas Rio Vermelho, Baguá e Gameleira; no relatório da OM 049/1992, sobre diligência nas fazendas Rio Vermelho e Ouro Verde; no relatório da Delegacia Regional do Trabalho no Estado do Pará (DRT/PA), de 1994, sobre fiscalização na Fazenda Morada do Sol; e no ofício 030/1992 sobrescrito pelo Gabinete do Instituto Nacional de Seguro Social e Delegacia Regional do Trabalho do Pará (DRT/INSS/GAB), que avalia o trabalho de fiscalização do Ministério do Trabalho e Emprego (MTE) em relação às denúncias de trabalho escravo nas fazendas do Pará. A precariedade das condições de vida e de trabalho, a apreensão de armas encontradas com fiscais - designação dos pistoleiros - e o manifesto desejo dos trabalhadores em aproveitar a presença da polícia e, em alguns casos, de fiscais do trabalho, para deixar o local, não eram suficientes para qualificarem as denúncias. 
O Relatório de Missão (RM) 018, de 9 de fevereiro de 1989, apresentado pela delegacia de polícia federal de Marabá, atendendo à solicitação de investigação do MPF, é síntese das argumentações que atravessam quase todos esses documentos oficiais. A PF identifica quatro empreiteiros, gatos, atuando na Fazenda Brasil Verde: Mano Velho, como era conhecido Manoel Ferreira Pinto, acusado pelo desaparecimento dos menores Iron Canuto e Miguel Ferreira, que tinha sob seus serviços 39 trabalhadores; Zé bigode, que fugiu com a aproximação da polícia; Jonas David, que a polícia não visitou porque se encontrava numa área "inacessível da fazenda"; e Antônio de Sousa Filho, com 12 trabalhadores lhe prestando serviço de roço de juquira. Sobre o desaparecimento dos menores, sem indicar que se procedeu à investigação mais minuciosa, os agentes consideram satisfatória a resposta que ouviram dos próprios trabalhadores, de que são livres para ir e vir. Contraditoriamente, no mesmo parágrafo, declaram que ouviram que "é normal trabalhadores fugirem, principalmente quando estão devendo" (RM 018/89, Fls 04). Segundo os agentes, "a única reclamação foi o baixo preço pago pela fazenda por alqueire de juquira roçado" (idem). Depois de negarem o objeto da denúncia, ou seja, o trabalho escravo, apresentam o esquema de aliciamento e produção do endividamento para concluírem que dos trabalhadores "tudo é descontado no serviço, fato que muitas vezes são proibidos de deixar o serviço por causa da dívida" (idem). A incongruência atravessa todo o relatório e é indicativa de uma alteridade de sujeitos e de cosmos. 0 trabalhador rural é 0 outro em negativo. Todas as condições da escravidão são percebidas, mas o que não está dito é que falta o reconhecimento dos sujeitos enredados nesse sistema de exploração.

À ideia de que os trabalhadores do campo não são sujeitos de direito somava-se a falta de tipificação legal do que seria reduzir alguém à condição análoga à de escravo. Assim, tornou-se conveniente, aos agentes públicos, a negação do crime com base na falta de estrutura da escravidão moderna - aquela que persistiu legalmente até 1888 - e, pela inexistência daquele mesmo quadro, negavam a reinvenção, sob outras condições, do fenômeno supostamente pretérito. Havia o trabalho sob coerção, havia a precariedade das condições de vida e de trabalho, havia o adoecimento, e havia denúncias de mutilação, espancamento e assassinato de trabalhadores; contudo, faltava o pelourinho, faltava a senzala. Então, no entendimento desses agentes públicos, inexistiam os requisitos fundamentais para a tipificação da norma penal.

Divergindo dessa argumentação, a perspectiva do olhar dos agentes pastorais tem como referência a concretude da dor e da violência encarnada na exploração a que são submetidos os trabalhadores que, em muitos casos, como relata Figueira $(2004 ; 2008)$ batem à porta das casas paroquiais e dos escritórios da CPT em busca de alguma ajuda e proteção. 0 trabalho 
escravo diz respeito, nessa acepção, às circunstâncias em que a dignidade dos trabalhadores está afetada. Nesse contexto, o debate, suscitado sobretudo em função do trabalho dos agentes pastorais, especialmente a militância de frei Henri, não foi circunscrito à questão terminológica. A trajetória jurídico-pastoral de Henri, bem como o trabalho pastoral e intelectual de Ricardo Rezende Figueira e de muitos outros agentes pastorais, demostra a disputa em torno da dignidade humana dos trabalhadores rurais, negada por uns, os agentes públicos, e afirmada por outros, os agentes pastorais. A reformulação do artigo 149 nasceu desse embate e, em meio a tantos desafios prementes, representa uma conquista importante para os trabalhadores e seus aliados, sobretudo quando se considera, como é o caso, que essa reformulação funciona como estratégia para minar a resistência das autoridades públicas em reconhecer os trabalhadores como sujeitos de direito.

Para Lélio Bentes Correa e Ela Wiecko Volkmer de Castilho (apud Silva, 2016: 124-125), o trabalho dos agentes pastorais demandava ações legais nas quais o Código Penal era impreciso e, por isso, insuficiente. Ela Wiecko pondera, inclusive, que os fatos apresentados pela Comissão Pastoral da Terra constituíam fenômeno que o direito brasileiro não estava preparado para enfrentar. Havia o crime, mas não havia a tipificação do crime. Era preciso, portanto, uma reconfiguração da lei à luz das demandas que eram apresentadas à Justiça. Foi nesse aspecto que o frei Henri Burin des Roziers contribuiu significativamente.

As primeiras experiências de engajamento nos movimentos sociais do frade dominicano Henri Burin des Roziers, ${ }^{7}$ que chegou ao Brasil em dezembro de 1978, se deram a partir do seu envolvimento com a efervescência francesa dos anos 1960 e do apoio aos trabalhadores imigrantes em situação de risco sob a exploração das grandes empresas em seu país. 0 serviço militar na Argélia, anterior ao ingresso na Ordem Dominicana, já Ihe teria marcado o espírito no sentido da solidariedade humana. Logo após sua graduação em Direito, junto com o frade Jean Raguenés, Henri apoiou, no Centro Saint Yves, o movimento estudantil de maio de 1968, que o teria influenciado a se aproximar da cultura popular e dos problemas do povo pobre da França. Recusando-se à vida internada no convento, mudou-se para o leste da França, onde trabalhou na construção civil como operário e, no retorno à Paris, na Rhodia. Da experiência nas grandes fábricas, ajudando a organizar os trabalhadores para resistir contra a superexploração, Henri conclui que "a fábrica era uma máquina de precisão. Mas as condições de trabaIho e alojamento eram péssimas. Os trabalhadores eram alojados nos porões das fábricas, e tudo era muito sujo" (apud Silva, 2011: 143).

A origem aristocrática de Henri des Roziers e a sua trajetória intelectual também são elementos importantes para a sua atuação no Brasil. 0 marco referencial de constituição do 
poder da família Roziers remonta à resistência contra a ocupação nazista. Nesse contexto, e no governo que se formou depois da Guerra, alguns membros da família ocuparam cargos proeminentes na burocracia do Estado Francês. Trata-se de uma família aristocrática, cujos membros eram engenheiros, diplomatas, militares, economistas e juristas. 0 próprio Henri, depois de se formar em Direito, doutorou-se, aos 28 anos, com uma tese sobre a diferença entre o direito civil comercial e a legislação inglesa, premiada como a melhor tese do ano de 1959 da Universidade de Paris. Embora esse perfil contraste com a imagem do homem que podia facilmente ser encontrado de short, camisa simples e sandálias entre os camponeses da Amazônia, essa dimensão contribui para que se entenda a legitimidade que o jurista europeu, com registro na Ordem dos Advogados do Brasil (OAB), seção Pará, teve entre os operadores do direito brasileiros, e para que se conjecture o poder da sua mediação muito além do trabaIho comum do vigário de alguma paróquia do sul do Pará.

Henri chegou ao Brasil em 1978 e, depois de uma breve ambientação ao País com uma estadia inicial no Rio de Janeiro, foi convidado a colaborar com o Regional Araguaia-Tocantins, da CPT, circunstância em que conheceu, especialmente no Bico do Papagaio, a dureza da luta que vitimava homens e mulheres, especialmente lideranças sindicais. Não tendo ainda registro da $O A B$, assessorava o advogado Osvaldo de Alencar Rocha, encampando uma luta jurídica pouco frutífera, que tentava garantir aos posseiros o direito de permanecer em suas posses. Além dessa luta jurídica, os agentes pastorais procuravam acompanhar e apoiar as famílias despejadas. 0 arbítrio era a marca dos despejos. Os fazendeiros requeriam a desocupação de uma área, mas usavam a liminar para retirar, com o apoio da polícia e de pistoleiros, famílias de outras áreas. Incendiavam casas e roças, e os próprios juízes que concediam essas liminares estavam, também eles, como era o caso do juiz de Araguaína, João Batista de Castro Neto, comprometidos com a grilagem (idem). Esse era o caráter do trabalho da CPT não só no Bico do Papagaio, âmbito geográfico do Regional Araguaia-Tocantins, como também no sul do Pará e, de modo mais geral, na República, que, naquele momento, caminhava a passos largos rumo à redemocratização, enquanto, no campo, jorravam sangue e suor no confronto aberto entre um projeto que queria terra para trabalhar e outro que privava a terra como forma de obtenção de renda. Nesse sentido, não há dúvida de que, paradoxalmente, o pico da violência agrária na Amazônia se deu na metade da década de 1980, com o fim do regime ditatorial. 0 assassinato do padre Josimo Moraes Tavares e a conjuntura que o assassinou constituem argumentos eloquentes dessa interpretação.

A morte do padre Josimo indica a seletividade da violência. De uma longa história de crueldades contra os camponeses em geral, passou-se à violência diretamente contra suas 
lideranças ou contra as lideranças que os apoiavam. Em Rio Maria, sul do Pará, tornou-se emblemático o caso dos assassinatos de lideranças sindicais ligadas ao Sindicato dos Trabalhadores Rurais. Para o padre Ricardo Rezende, naquele momento histórico, "tornar-se presidente do Sindicato dos Trabalhadores Rurais de Rio Maria [...] era assinar uma sentença de morte" (apud Silva, 2016: 214). Havia uma lista dos marcados para morrer (Figueira, 2008; Gallo, 2008), que, de fato, morriam. Foi assim que, entre os marcados, mataram os presidentes do Sindicato dos Trabalhadores João Canuto, em 1985, e, depois, Expedido Ribeiro de Souza, em 1991. Nesse contexto de assassinatos seletivos à custa da inércia dos agentes públicos e do pouco caso da Justiça, frei Henri Burin des Roziers, à época com dificuldades para trabalhar na Diocese de Tocantinópolis, aceitou o convite para colaborar em Rio Maria, circunscrição eclesiástica da Diocese de Conceição do Araguaia.

A experiência de atuação com os trabalhadores em situação de degradação na França contribuiu para que Henri, na leitura da violência agrária, se sensibilizasse com as condições dos trabalhadores submetidos à escravidão. 0 primeiro grande acontecimento de que Henri participou em Rio Maria foi o Fórum Nacional Permanente Contra a Violência no Campo, que nasceu como estratégia de articulação entre os vários atores, entre eles a CPT, que se comprometeram com o enfrentamento à violência agrária que afetava principalmente posseiros, trabalhadores e lideranças sindicais. No arranjo para a criação do fórum foi importante o papel do padre Ricardo Rezende Figueira (ele próprio ameaçado de morte), que tinha trânsito entre intelectuais, artistas, políticos e operadores do direito e que, com 0 apoio de outros setores organizados da sociedade, fez repercutir internacionalmente 0 assassinato do líder sindical Expedito Ribeiro de Souza. Ainda, atraíram, no evento de massa que marcou o início do fórum, a atenção do grande público brasileiro, sensibilizando a opinião pública para o que se passava no sul do Pará. Henri participou do fórum e, depois que quase todos deixaram o sul do Pará, inclusive o padre Ricardo Rezende Figueira, ${ }^{8}$ continuou na região, enfrentando os senhores da morte e da escravidão.

A atuação do frei Henri em Rio Maria implicou uma mudança de perspectiva no trabalho da CPT. O foco, aos poucos, se deslocou da questão da terra para a violência nas relações trabalhistas. Os agentes reconheciam o trabalho escravo na região desde 1972 (Bispo de..., 1972), mas predominava a atenção à violência contra os posseiros. Os problemas não só eram concomitantes, como também estavam relacionados. Até a década de 1990, no entanto, sobressaíam as denúncias de violência contra os posseiros, incluindo as cartas pastorais de Casaldáliga (1970; 1971), que tratavam o trabalho escravo como elemento na conjuntura da violência agrária. 0 escopo era a luta pela terra e a consequente violência decorrente 
dessa luta. A forma da militância de Henri, pelo direito à dignidade dos trabalhadores, não só colocou o debate sobre o trabalho escravo na ordem do dia, como também coadjuvou com uma nova compreensão do fenômeno que repercutiu no campo jurídico. Henri acolhia trabalhadores que fugiam das fazendas, denunciava e, principalmente, cobrava providências em relação às denúncias. 0 caso da Fazenda Brasil Verde ilustra sua estratégia de ação. Os arquivos da CPT ${ }^{9}$ registram que em 25 de janeiro de 1989 foi apresentada denúncia de trabaIho escravo contra as fazendas Brasil Verde, de Xinguara-PA, e Belauto, no município de São Felix do Xingu-PA. Nesse documento, o agente pastoral informa que a denúncia já havia sido apresentada, em 21 de dezembro de 1988, ao Ministério Público e à Superintendência da PF, em Belém, e, portanto, tratava-se de uma cobrança de providências com ênfase no fato de que os Quagliato, proprietários das fazendas denunciadas, continuavam a praticar o trabalho escravo sem que o Poder Público os incomodasse. As diligências da PF terminaram por concluir pela improcedência das denúncias, como já se demonstrou.

Henri se debruçava sobre esses processos e não se satisfazia com a conclusão dos agentes públicos. Tanto é que ele, em 18 de março de 1992, reapresentou ao MPF cópia das denúncias feitas em 1989 contra a Fazenda Brasil Verde ${ }^{10}$ e Belauto por prática de trabalho escravo, e cobrou informações ao órgão público sobre o encaminhamento dado às referidas denúncias. A Procuradoria-Geral da República (PGR), por meio do ofício 706 da Secretaria de Coordenação da Defesa dos Direitos Individuais e dos Interesses Difusos (SECODID), como resposta, informou a Henri a abertura de processo nº 08100.001318/92-19 contra a Fazenda Brasil Verde, com data de 22 de abril de 1992 . 0 processo, no entanto, era uma formalidade que implicou apenas a solicitação da PGR de nova diligência à PF nas fazendas denunciadas. Depois de três meses sem resposta às suas indagações, Henri voltou a cobrar a PGR, que, novamente, reiterou, mediante o ofício 1.556/SECODID, solicitação de diligência à PF. Passados oito meses, um memorando da PF, o de $n^{\circ}$ 1318/92/DPF, assinado por José Carlos Fortes de Carvalho, da delegacia de Marabá, respondeu à PGR que em 1989 teria ocorrido uma diligência nas fazendas denunciadas e que, não tendo sido confirmadas as denúncias à época, não se justificava abertura de inquérito, tampouco de novas investigações.

A luta encampada por frei Henri, que passava pela sensibilização do Judiciário brasileiro à causa do trabalhador, era no sentido de reconhecer esses sujeitos como sujeitos de direito. Segundo Lélio Bentes, à época procurador federal (Silva, 2016: 173), os agentes públicos, sobretudo as polícias e o Judiciário, habituados a reprimir os grupos sociais marginalizados, não estavam preparados para esse tipo de demanda apresentada pela CPT. As denúncias e o conjunto comprobatório que frei Henri passou a constituir, inclusive com a apresentação das 
vítimas no cenário público, passaram a incomodar a Justiça brasileira, que, não podendo ignorar mais o problema, precisava reconhecer a sua inabilidade para fazer o enfrentamento necessário.

Os então procuradores Lélio Bentes e Ela Wiecko, sensibilizados com a causa dos trabaIhadores, recordam (idem) que, em várias reuniões organizadas por políticos e pela própria Procuradoria do Trabalho em Brasília, Henri levou trabalhadores vítimas de trabalho escravo que contavam o seu drama e sensibilizavam os ouvintes. Mas, apesar do drama das narrativas, a imprecisão do Código Penal dificultava a ação do MP. 0 que parecia mais latente nas discussões sobre o tema que aconteciam no âmbito do Fórum Permanente Contra a Violência no Campo era a questão da dignidade do trabalhador. Os participantes do fórum - provocados por essa metodologia de trabalho pastoral de Henri, que encarnava o drama do trabalho escravo na figura dos homens simples, que muitas vezes apresentavam-se com os sinais da escravidão gravados em seus corpos - criaram um grupo de trabalho dentro para discutir especificamente o trabalho escravo. Foi nessa conjuntura que surgiu o "Seminário Trabalho Escravo Nunca Mais", em que os limites legais para o enfrentamento do trabalho escravo se tornaram tema específico das discussões e em que foram constituídas as diretrizes para o projeto que resultou na Lei $n^{\circ} 10.803$, de 11 de dezembro de 2003.

É importante ressaltar que o fórum agregava uma diversidade de sujeitos e organizações. Além da CPT, contava com a participação de agentes políticos, de órgãos do governo, especialmente do MTE, de setores organizados da sociedade, como a OAB, de outras entidades não governamentais, e das organizações trabalhistas. Muitos encontros se deram no espaço da Câmara dos Deputados, em Brasília. Essa diversidade de sujeitos engajados no enfrentamento do trabalho escravo foi imprescindível para a elaboração e a tramitação do projeto de lei que resultou na promulgação da Lei n 10.803/2003, que alterou o artigo 149 do Código Penal.

Como nas denúncias a dignidade dos trabalhadores aparecia recorrentemente como valor a ser resguardado pelo Poder Público, a Lei $n^{\circ} 10.803 / 2003$ foi muito além da criminalização das condutas tipificadas no documento de Casaldáliga. Na nova redação do artigo 149 do Código Penal, ao criminalizar a submissão de alguém à condição análoga à de escravo, o texto define o fato como a circunstância em que o trabalhador é forçado ao trabalho, submetido a jornada exaustiva, a condições degradantes de trabalho ou, ainda, tem restringida sua locomoção. A primeira grande novidade, além da tipificação em si, é que qualquer desses elementos, isoladamente - trabalho forçado, jornada exaustiva, condições degradantes e restrição da locomoção do trabalhador -, é suficiente para a constituição do crime de trabalho escravo. A lei também passa a enquadrar toda a rede que sustenta esse crime. Sujeitos e práticas são tipificados. 0 texto criminaliza o papel do empreiteiro, que no sistema escravista 
cria a dívida e impede o trabalhador de abandonar o serviço sob o pretexto de pagá-la. Define como copartícipe quem, sob qualquer pretexto, inclusive de dívida, cerceia o uso de transporte pelos trabalhadores para deixar o local de trabalho. Enquadra os fiscais, ou guardas, que dentro do sistema escravista são pistoleiros que personificam a violência como ameaça perene. Segundo a nova redação da lei, também incorre no crime de trabalho escravo quem mantém vigilância ostensiva e se apodera de documentos ou de objetos pessoais dos trabalhadores com o objetivo de mantê-los no local de trabalho.

A luta que desaguou nessa vitória importante, embora parcial, não foi a de um homem ou de uma organização apenas. A luta foi e é um processo, e nesse processo foi e é fundamental a articulação com diversos setores da sociedade organizada, comprometidos com a defesa da vida e da dignidade humanas. Além disso, tanto a CPT quanto os operadores do direito recorreram a instâncias internacionais. A CPT buscou, nos organismos internacionais, pressionar o governo brasileiro, especialmente nos casos de José Pereira e da Fazenda Brasil Verde; os operadores do direito buscaram, no direito internacional, referências legais para as ações relativas ao trabalho escravo. Essas posições convergiram, sobretudo no espaço do fórum, para que se avançasse na criminalização de condutas que, tipificadas como escravistas, atentavam contra a dignidade do trabalhador.

Articulação, pode-se dizer, é o fundamento da ação pastoral de Henri des Roziers. Mas não só dele. 0 trabalho de Ricardo Rezende, que Ihe antecedeu na região, era também de busca por sensibilizar a opinião pública e de parcerias para o enfrentamento à violência no campo, inclusive o trabalho escravo. Empreendeu-se, com certo êxito, uma sensibilização que passava pelo envolvimento de artistas, políticos e autoridades públicas, tendo Henri des Roziers e Ricardo Rezende como articuladores desse "recrutamento". 0 trabalhador isolado estava suscetível aos desmandos do patrão. 0 posseiro isolado estava suscetível à violência do grileiro. 0 agente pastoral isolado podia ser assassinado mais facilmente, e a CPT, isolada, podia sucumbir. A formação de um coletivo de sujeitos sociais engajados na mesma causa é que constituía, e constitui, a força capaz de garantir trabalho digno, terra a quem a ocupava, e vida longa aos sujeitos na luta. O Fórum Nacional Permanente Contra a Violência no Campo foi expressão desse coletivo de sujeitos. A própria produção acadêmica sobre o trabalho escravo, que vem crescendo significativamente, ${ }^{11}$ ocorre em função desse trabalho de sensibilização e visibilidade. É dessa articulação, empreendida não apenas por Ricardo ou Henri Des Roziers, que resultou a visibilidade que pôs o trabalho escravo em evidência, vexou o governo brasileiro, mobilizou parlamentares, e questionou a própria eficácia dos mecanismos legais, que foram alterados, e continua incitando toda a sociedade a se engajar na luta contra essa forma de exploração dos trabalhadores. 
Concluindo, é importante dizer que a mediação, ${ }^{12}$ sobretudo aquela empreendida por frei Henri Burin Des Roziers no sul do Pará, é modelo analítico da atuação da CPT na defesa da dignidade dos trabalhadores do campo e do processo de amadurecimento dessa luta. A forma dessa atuação foi impactante na medida em que contribuiu para a alteração do artigo 149 do Código Penal e, assim, por força da própria realidade, forjou uma ampliação do conceito de trabalho escravo. Os elementos textuais da lei atual constavam nas denúncias formuladas pela CPT, mas não havia meios legais de enfrentamento. 0 avanço, portanto, foi fruto do esforço de convencimento de alguns homens e mulheres responsáveis pela aplicação da lei, bem como da sensibilização de legisladores que se comprometeram com as mudanças dos dispositivos legais, de modo a possibilitar medidas efetivas de enfrentamento do trabalho escravo.

Depois desse avanço, o que se nota atualmente é um esforço retroativo encampado pelo setor ligado ao agronegócio: querem revisar novamente o artigo 149 do Código Penal para suprimir as conquistas criadas pela Lei $n^{\circ} 10.803 / 2003$. Esse grupo já logrou êxito por meio da reforma trabalhista, que, ao possibilitar o contrato de trabalho intermitente, esvazia a possibilidade punitiva quando o objeto da denúncia de trabalho escravo for fundamentado na jornada exaustiva. É preciso lembrar também que no Governo Temer chegou-se a editar, em 2017, uma portaria que retirava dos critérios de fiscalização do trabalho escravo a jornada exaustiva.

A onda conservadora avança. Os senhores do capital querem conservar tudo para si, e estão comprometidos a não deixar nada aos trabalhadores. E o que fizeram até aqui parece ser apenas o início de um amplo movimento em prol de uma reforma conservadora, que pretende subtrair os direitos fundamentais dos trabalhadores e trabalhadoras, especialmente no campo. As articulações pelo fim do MTE e da Justiça do Trabalho constituem um retrocesso sem precedentes na luta contra o trabalho escravo. Os grupos de fiscalização móvel têm, desde o início do Governo Temer, sofrido sérias restrições, que agora tendem a aumentar. 0 novo presidente eleito já fez várias declarações públicas sobre a inconveniência da existência de um Ministério Público do Trabalho, e tudo indica que vai prevalecer, como política de Estado, a ideia de que o mais importante para a nação é melhorar os números sobre a produção de riquezas, independente de quem se beneficia dessas riquezas e das circunstâncias em que elas são produzidas.

Frei Henri Burin des Roziers faleceu em Paris no dia 26 de novembro de 2017, mas a CPT, as demais organizações engajadas e os muitos sujeitos individuais e coletivos comprometidos com a defesa dos mais pobres, especialmente os pobres do campo, continuam vivos e firmes, espalhados entre instituições como a OAB, no Pará, a Universidade Federal do Sul e Sudeste do Pará (Unifesspa) e muitos outros espaços que, em tempos sombrios, são luz que promete manter viva a chama da esperança por dias melhores. 


\section{NOTAS}

1 A literatura desde o início do século XX, a exemplo de Euclides da Cunha (1999), Hugo de Carvalho Ramos (2014), e, mais tarde, Bernardo Élis (1979), já indicava que, em Goiás ou na Amazônia, o homem do campo só trabalhava para se endividar, e precisava continuar trabalhando porque tinha dívidas a serem quitadas.

2 José de Souza Martins tem posicionamentos claramente diferentes, em tempos e lugares distintos. Entre as décadas de 1970 e 1980, esteve alinhado ao trabalho da CPT e de grupos políticos de esquerda, a ponto de assessorá-los. A partir da segunda metade da década de 1990, quando se aproximou do governo de Fernando Henrique Cardoso, tornou-se crítico ácido do trabalho da CPT, a quem passou a conceber como denuncista (Martins, 1999), e qualificou de ingênua (ibidem, 2000) a compreensão dos conceitos com que os agentes interpretavam a realidade, o que, segundo ele, dificultava o diálogo e a solução dos problemas sociais do campo.

3 Pinto e Vieira explicam que, considerando a procedência dos trabalhadores, os escravizados no Pará podem ser classificados em três grupos: os moradores, os peões do trecho e os trabalhadores de fora. 0 peão é definido como "um sujeito desgarrado, que de patrimônio só tem a sacola em que carrega seus pertences pessoais" (2006: 49). Segundo Figueira (2004: 142) "trata-se de indivíduos que sempre no trecho, em qualquer lugar estão deslocados, e são marginais até em relação aos escravizados da categoria moradores e trabalhadores de fora (Silva, 2016).

4 Esses documentos são físicos e estão disponíveis no arquivo da CPT Araguaia-Tocantins, escritório de Xinguara, Pará. Em 2014, a partir de uma parceria com a Universidade Federal do Tocantins (UFT), iniciou-se um processo de digitalização do arquivo, tendo em vista a integração com o arquivo digital da CPT Nacional, que já disponibiliza uma série de documentos sobre conflitos agrários e trabalho escravo por meio digital.

5 Dessa denúncia resultou a apresentação de reclamação (Cejil, 1998) contra a omissão do governo brasileiro à Corte Interamericana de Direitos Humanos.

6 Assim como as notas jornalísticas citadas neste estudo, os demais documentos, incluindo os relatórios da Polícia Federal e dos fiscais do Ministério do Trabalho e Emprego, os documentos do Ministério Público Federal e algumas correspondências oficiais, como os ofícios da CPT, fazem parte do arquivo da CPT Araguaia-Tocantins, escritório de Xinguara. Esses documentos foram pesquisados e digitalizados, com autorização dos responsáveis, entre 2009 e 2015, no contexto de pesquisa de mestrado e doutorado. Muitos deles encontram-se, hoje, disponíveis por meio digital a partir do Centro de Documentação Dom Tomás Balduíno (Cedoc), acessível no link: http://goo.gl/TJ10G.

7 As informações biográficas de Henri Burin des Roziers foram levantadas em duas entrevistas realizadas no contexto de uma pesquisa de mestrado cujo foco era a violência agrária no Araguaia-Tocantins. A primeira ocorreu em Xinguara, Pará, em agosto de 2009. Naquela ocasião, já com a saúde debilitada, frei Henri recebeu o entrevistador, que foi seu hóspede por uma semana. Posteriormente, depois da análise da transcrição do primeiro encontro, uma nova entrevista foi realizada, dessa vez em Brasília, em 13 de fevereiro de 2010.

80 trabalho de Ricardo Rezende Figueira no sul do Pará foi intenso. Embora se destacasse nas práticas de denúncia da violência contra os trabalhadores, especialmente a violência seletiva contra as lideranças do sindicato dos trabalhadores rurais, sua facilidade de trânsito entre personalidades de diferentes segmentos sociais, como políticos, jornalistas, juristas, artistas e intelectuais foi fundamental para a constituição de uma rede de apoio ao trabalho da CPT, que desaguou no Fórum Nacional Permanente Contra a Violência no Campo. Desde a década de 1980, já ensaiava interpretações teóricas à violência agrária no sul do Pará e, a partir da segunda 
metade da década de 1990, mudou-se para o Rio de Janeiro, onde, gradativamente, deslocou a perspectiva da sua militância. De padre do interior batendo às portas de delegacia ou encaminhando baleados a hospitais, passou ao papel do intelectual engajado na produção de saber acadêmico sobre a escravidão contemporânea. Dessa nova fase, entre dezenas de artigos científicos, destaca-se sua tese de doutoramento sobre o trabalho escravo contemporâneo (Figueira, 2004), que se tornou marco referencial nas discussões sobre o tema.

9 ofício da CPT ao Conselho de Defesa dos Direitos da Pessoa Humana (CDDPH), com data de 25 de janeiro de 1989.

10 As reincidências de denúncia de trabalho escravo na Fazenda Brasil Verde levaram, em 2016, à condenação do Brasil pela Corte Interamericana de Direitos Humanos, com base numa denúncia apresentada ao MPF, em 2000, por negligência no combate ao trabalho escravo.

11 A pesquisa de Rodrigo Garcia Schwarz (2014) indica que, até 1999, apenas 2 trabalhos acadêmicos stricto sensu tinham como tema o trabalho escravo, tendo sido o primeiro em 1992. Schwarz, no entanto, ignora o estudo pioneiro de Neide Esterci, de 1987, o que pode ser explicado pelo fato de que a Coordenação de Aperfeiçoamento de Pessoal de Nível Superior (Capes) disponibiliza dados de pesquisas realizadas a partir de março de 2001. Sua pesquisa, no entanto, tem, entre outros, o mérito de demonstrar que o interesse sobre o tema tem crescido. Schwarz indica que, entre 2013 e 2015, foram concluídas 45 pesquisas sobre trabalho escravo ligadas aos programas de pós-graduação stricto sensu e, destas, 10 foram em nível de doutorado, e 35, de mestrado.

12 Para efeito deste estudo, o conceito de mediação está ligado ao de intelectual orgânico, e tem como referência as proposições de Antônio Gramsci (1989). Para a compreensão da mediação, que é resultado de uma militância intelectual dos agentes da CPT, é importante a reflexão sobre as estratégias utilizadas por Henri Burin des Roziers e Ricardo Rezende Figueira no momento em que a violência mais intensa atingia sindicalistas, posseiros e trabalhadores no sul do Pará. Os mediadores repercutem as denúncias apresentadas pelos trabalhadores e procuram estabelecer uma rede de solidariedade que contribui com a visibilidade da violência contra os trabalhadores.

\section{REFERÊNCIAS BIBLIOGRÁFICAS}

BAUMAN Zygmunt. A cultura no mundo líquido moderno. Trad. de Carlos Alberto Medeiros. Rio de Janeiro: Zahar, 2013.

BRASIL. Código penal brasileiro. Brasília: Senado Federal, 1940.

CERTEAU, Michel. A escrita da história. Tradução de Maria de Lourdes Menezes. Rio de Janeiro: Forense Universitária, 1982.

CUNHA, Euclides da. À margem da história. São Paulo: Martins Fontes, 1999.

ÉLIS, Bernardo. A enxada. In: . Veranico de janeiro. 4. ed. Rio de Janeiro: José Olímpio, 1979.

ESTERCI, Neide. Conflito no Araguaia: peões e posseiros contra a grande empresa. Petrópolis: Vozes, 1987. . Imobilização por dívida e formas de dominação no Brasil de hoje. Lusotopie, n. 3, p. 123-137, 1996. Escravos da desigualdade: um estudo sobre o uso repressivo da força de trabalho hoje. Rio de Janeiro: Ceps, 2008. 
FIGUEIRA, Ricardo Rezende. Pisando fora da própria sombra: a escravidão por dívida no Brasil contemporâneo. Rio de Janeiro: Civilização Brasileira, 2004.

Por que o trabalho escravo? Estudos Avançados, São Paulo, vol. 14, n. 38, p. 31-50, 2000.

Rio Maria: canto da terra. Rio de Janeiro: Civilização Brasileira, 2008.

FRANCO, Maria Sylvia de Carvalho. Homens livres na ordem escravocrata. 4. ed. São Paulo: Editora da Unesp, 2008.

GRAMSCl, Antônio. Os intelectuais e a organização da cultura. São Paulo: Civilização Brasileira, 1989.

JASMIN, Marcelo Gantus; JÚNIOR, João Feres (Org.). História dos conceitos: debates e perspectivas. Rio de Janeiro: Editora PUC-Rio/Loyola, 2006.

KOSELLECK, Reinhart. Uma história dos conceitos: problemas teóricos e práticos. Estudos Históricos, Rio de Janeiro, vol. 5, n. 10, p. 134-146, 1992.

LIMA, Nísia Trindade de. Um sertão chamado Brasil. 2. ed. São Paulo: Hucitec, 2013.

MARTINS, José de Souza. A escravidão nos dias de hoje e as ciladas da interpretação. In: VV.AA. (org.). TrabaIho escravo no Brasil contemporâneo. São Paulo: Loyola/CPT, 1999.

. A reprodução do capital na frente pioneira e o renascimento da escravidão no Brasil. Tempo Social

- Rev. Sociol. USP, São Paulo, vol. 6, n. 1-2, p. 1-25, 1995.

Fronteira: a degradação do outro nos confins do humano. São Paulo: Hucitec, 1997.

Reforma agrária: o impossível diálogo. São Paulo: Edusp, 2000.

PINTO, Ana de Souza; VIEIRA, Maria Antonieta da costa. 0 perfil do trabalhador escravizado no Pará. In: SAKAMOTO, Leonardo (Coord.). Trabalho escravo no século XXI. Brasília: OIT, 2006.

RAMOS, Hugo de Carvalho. Gente de gleba. In: Tropas e boiadas (contos). São Paulo: Poeteiro Editor Digital, 2014[1917].

SCHWARZ, Rodrigo Garcia. Terra de trabalho, terra de negócio: o trabalho escravo contemporâneo na perspectiva (da violação) dos direitos sociais. São Paulo: LTR, 2014.

SILVA, Moisés Pereira. O trabalho escravo contemporâneo e a atuação da CPT no campo (1970 - 1995). 2016. Tese (Doutorado) - Pontifícia Universidade Católica de São Paulo, São Paulo. 2016.

Padre Josimo Moraes Tavares e a atuação da Comissão Pastoral da Terra (CPT) nos conflitos agrários do Araguaia-Tocantins (1970-1986). 2011. Dissertação (Mestrado) - Universidade Federal de Goiás, Goiânia. 2011.

\section{DOCUMENTÁRIOS}

GALLO, Emilio. Esse homem vai morrer: um faroeste caboclo. [Filme-vídeo]. Direção de Emilio Gallo. Brasil. $75 \min , 2008$.

RAMPAZZO, Alexandre. Nas terras do bem virá. Direção: Alexandre Rampazzo. Produção: Eclipse Produções/ Varal Filmes. Brasil. 110min, 2007. 


\section{DOCUMENTOS}

BRASIL. Lei $n^{\circ}$ 10.803, de 11 de dezembro de 2003.

CASALDÁlIGA, Pedro. Escravidão e feudalismo no Norte do Mato Grosso. São Félix do Araguaia: 1970. Mimeo.

. Uma igreja da Amazônia em conflito com o latifúndio e a marginalização social. São Feliz do Araguaia: Prelazia de São Felix, 1971.

CEJIL. CPT e CEJIL apresentam denúncia contra o Estado Brasileiro por negligência na investigação de trabaIho escravo na Fazenda Brasil Verde. Washington-DC, 21 de outubro de 1998.

COMISSÃO PASTORAL DA TERRA. Ofício da CPT ao CDDPH. Xinguara, 25/01/1989. Arquivo CPT Xinguara.

DEPARTAMENTO DE POLÍCIA FEDERAL. Relatório de Missão 018/89/DPF/PA. Marabá: DPF, 1989. Arquivo CPT Xinguara.

. Ordem de Missão 036/92/DPF/MBA-PA. Marabá: DPF, 1992. Arquivo CPT Xinguara.

. Ordem de Missão 049/92/DPF/PA. Marabá: DPF, 1992. Arquivo CPT Xinguara.

. Memorando 1318/92 DPF/MPF/PGR. Brasília: MPF, 1992. Arquivo CPT Xinguara.

MINISTÉRIO DO TRABALHO E EMPREGO. Ofício 030/92 DRT/INSS/GAB. Belém: MTE, 1992. Arquivo CPT Xinguara.

Relatório SRT/DRT/PA. Belém: MTE, 1989. Arquivo CPT Xinguara.

PROCURADORIA-GERAL DA REPÚBLICA. Ofício 706/92 SECODID. Brasília: PGR, 1992. Arquivo CPT Xinguara.

. Ofício 1556/92 SECODID. Brasília: PGR, 1992. Arquivo CPT Xinguara.

. Processo 08100.003158/92-15. Brasília: PGR, 1992. Arquivo CPT.

\section{JORNAIS}

COUTINHO, Luiz Paulo; BARBOSA, Rubens. Desamparo, a recompensa ao peão escravo da Amazônia. Jornal do Brasil, 22 de abril de 1973. Caderno 1, p. 34. Arquivo CPT Xinguara.

BISPO DE Marabá denuncia: superior dominicano ameaçado de morte. O Liberal, Belém, 10 de maio de 1972. Arquivo CPT Xinguara.

Trabalho Escravo é denunciado por peões em Xinguara. O Liberal, Belém, 24 de janeiro de 1989. Primeiro Caderno, p. 9. Arquivo CPT Xinguara. 